\title{
On-line monitoring of solar cell module production by ellipsometry technique
}

\author{
M. Fried ${ }^{1,2}$ \\ ${ }^{1}$ Institute for Technical Physics and Materials Science, Research Centre for Natural Sciences (MTA TTK MFA), H- \\ 1525 Budapest, POB 49, Hungary \\ ${ }^{2}$ Doctoral School of Molecular - and Nanotechnologies, Faculty of Information Technology, University of \\ Pannonia, Egyetem u. 10, Veszprém, H-8200, Hungary
}

\section{Abstract}

Non-destructive analysing tools are needed at all stages of thin film photovoltaic (PV) development, and on production lines. In thin film PV, layer thicknesses, micro-structure, composition, layer optical properties, and their uniformity (because each elementary cell is connected electrically in series within a big panel) serve as an important starting point in the evaluation of the performance of the cell or module. An important focus is to express the dielectric functions of each component material in terms of a handful of wavelength independent parameters whose variation can cover all process variants of that material. With the resulting database, spectroscopic ellipsometry coupled with multilayer analysis can be developed for on-line point-by-point mapping and on-line line-by-line imaging.

This work tries to review the investigations of different types of PV-layers (anti-reflective coating, transparent-conductive oxide (TCO), multi-diode-structure, absorber and window layers) showing the existing dielectric function databases for the thin film components of CdTe, CIGS, thin Si, and TCO layers.

Off-line point-by-point mapping can be effective for characterization of non-uniformities in full scale PV panels in developing labs but it is slow in the on-line mode when only 15 points can be obtained (within 1 min) as a $120 \mathrm{~cm}$ long panel moves by the mapping station. In the last years [M. Fried et al, Thin Solid Films 519, 2730 (2011)], instrumentation was developed that provides a line image of spectroscopic ellipsometry (wl=350$1000 \mathrm{~nm}$ ) data. Upto now a single 30 point line image can be collected in $10 \mathrm{~s}$ over a $15 \mathrm{~cm}$ width of PV material. This year we are building a 30 and a $60 \mathrm{~cm}$ width expanded beam ellipsometer the speed of which will be increased by $10 \mathrm{X}$. Then 1800 points can be mapped in a 1 min traverse of a $60 * 120 \mathrm{~cm}$ PV panel or flexible roll-to-roll substrate.

e-mail: fried@mfa.kfki.hu

Introduction and trends in PhotoVoltaic Industry

Production and installation of PhotoVoltaic (PV) modules grew exponentially in the last decade. The thin film PV production and installation has grown similarly, or even faster, because its market share has grown from $5 \%$ upto $15 \%$. Presently, CdTe and $\mathrm{CuInGaSe}_{2}$ (CIGS) based thin film PV-s are overgrown the a-Si type PV-s. The best and average efficiences of all types of PV-modules are growing continuosly. At the same time, the relative fabrication cost (i.e. price of $\mathrm{Watt}_{\text {peak }}$ ) and energy pay-back time continuosly reducing and one can see from the so called "price learning curves" that the different thin film technologies are well ahead in cost effectiveness against the bulk crystalline Si-technologies. [Photovoltaics Report (Roland Schindler (Fraunhofer ISE) and Werner Warmuth (PSE AG)), Freiburg, December 11, 2012, www.ise.fraunhofer.de, FRAUNHOFER INSTITUTE FOR SOLAR ENERGY SYSTEMS ISE] 
Longitudinal elementary cells are connected electrically in series in thin film solar panels and the module power is limited by the elementary cell with the lowest current, so structural uniformity is essential to achieve high efficiency. If we want to close the gap between „Lab cell” and „Industrial module” efficiency, the key factor to increase the efficiency in the case of thin-film solar panels or modules is the lateral homogeneity.

\section{What can we measure on PhotoVoltaic structures by Spectroscopic Ellipsometry (SE)?}

The last decades have seen widespread use of SE in different fields of research. Ellipsometry offers great promise for characterization, monitoring, and control of a wide variety of processes, especially in semiconductor related areas [1-12]

\section{Micromorph silicon solar cell structures}

An understanding of the relationship between materials property and thin-film solar cell performance variations over large areas is of interest for evaluating the impact of macroscopic non-uniformities in scale-up from laboratory cells to production modules. One can spatially correlate the properties of the hydrogenated silicon (a-Si:H) i- and p-layers_as mapped over a larger substrate area-with device performance parameters from an array of a-Si:H based n-i-p dot cells. Analysis of the SE data over the full area provides maps of i-layer thickness and band gap, p-layer thickness and band gap, and p-layer surface roughness thickness for the n-i-p solar cell structure. The mapped values adjacent to the devices can be correlated with photovoltaic (PV) device performance parameters. When sufficient nonuniformity exists, these correlations enable optimization based on specific values of the fundamental properties. Alternatively, if the optimum set of properties has been identified, the impact of deviations due to macroscopic uniformities can be evaluated. [13]

\section{CIGS solar cell structures}

In the case of CIGS $\left(\mathrm{Cu}\left(\operatorname{In}_{1-x} \mathrm{Ga}_{\mathrm{x}}\right) \mathrm{Se}_{2}\right)$ the compositional change is an additional parameter. SE has the potential to map the alloy composition of CIGS thin films. This technique not only generates a compositional map but simultaneously provides maps of the more typical SE-determined properties as well, including bulk layer and surface roughness layer thicknesses. As a result, the methodology is suitable for characterization in online production-level applications. In order to develop the mapping capability, CIGS films having different molar Ga contents $\mathrm{x}$ and fixed copper stoichiometry were deposited and measured in situ by SE in order to extract the complex dielectric functions $\left(\varepsilon=\varepsilon_{1}+i \varepsilon_{2}\right)$ of these films. [14] For mathematical interpolation between the available alloy contents, the $\left(\varepsilon_{1}, \varepsilon_{2}\right)$ spectra were parameterized using an oscillator sum. Best-fitting equations were obtained that relate each oscillator parameter to the Ga content $\mathrm{x}$, as determined by energy dispersive $X$-ray analysis. This approach reduces the number of fitting parameters for $\left(\varepsilon_{1}, \varepsilon_{2}\right)$ from several to just one: the Ga content x. [15-18] Because $\left(\varepsilon_{1}, \varepsilon_{2}\right)$ is now represented by this single parameter, the chances of parameter correlations during fitting are reduced, enabling production-scale compositional mapping of chalcopyrite films by SE.

\section{Broadening of optical transitions in polycrystalline CdS and CdTe thin films}

The dielectric functions of polycrystalline $\mathrm{CdS}$ and CdTe thin films can be measured by in situ SE. Differences in due to processing variations are well understood using an excited carrier scattering model. A carrier mean free path can be defined that is found to be inversely proportional to the broadening of each of the band structure critical points (CPs). With this database, dielectric functions can be analyzed to evaluate the quality of materials used in CdS/CdTe photovoltaic heterojunctions. [19, 20] 
Using appropriate optical models, the characterization of the layer thickness and carrier properties becomes possible from SE analysis, even for textured surfaces.

\section{$\mathrm{SE}$ analysis of textured $\mathrm{SnO}_{2}: \mathrm{F}$ substrate}

The dielectric functions of the bulk $\mathrm{SnO}_{2}: \mathrm{F}$ layers are well represented using a Tauc-Lorentz oscillator term to describe the interband transitions and a Drude term to describe the free electrons. [21, 22] In order to express the complicated optical response in the textured structures, the optical model can incorporate (i) the surface roughness and interface layers calculated using an effective-medium-approximation multilayer model and (ii) the a-Si:H/SnO2:F structure divided into two regions with different thicknesses. [23]

\section{SE analysis of $\mathrm{ZnO}: \mathrm{Al}$}

$\mathrm{SE}$ measurements can be used to measure the dielectric function of the $\mathrm{ZnO}: \mathrm{Al}$ films. Monitoring of the electrical properties of $\mathrm{Al}$-doped $\mathrm{ZnO}$ layers by $\mathrm{SE}$ measurements are feasible by using the analytical expression suggested by Yoshikawa and Adachi [24], and the results show correlation between specific resistance and band gap energy and direct exciton strength parameter. [25]

\section{Characterization of $\mathrm{SiH}_{2}$ content in a-Si:H}

For hydrogenated amorphous silicon (a-Si:H) layers prepared by plasma-enhanced chemical vapor deposition, $\mathrm{SiH}_{2}$ bonds exist at the internal surface of the void-rich structure and light absorption reduces due to the void formation. In particular, the amplitude of the $\varepsilon_{2}$ spectra obtained from various a-Si:H layers is expressed completely by the $\mathrm{SiH}_{2}$ bond density in the a-Si:H and reduces strongly with increasing the $\mathrm{SiH}_{2}$ content, indicating that microvoids present in the a-Si:H network are surrounded by the $\mathrm{SiH}_{2}$ bonding state. Validity of $\mathrm{SiH}_{2}$ analysis can be confirmed from IR ellipsometry. [26]

\section{One remark}

We must note that there is not enough row material $(\mathrm{Cd}, \mathrm{Te}, \mathrm{In}, \mathrm{Se})$ for the best (CdTe, CIGS) thin film PV technologies if one think in TeraWatt scale! There is a hard need to research after new (High Concentration (concentration factor 300-1000 suns) Photovoltaic Systems i.e. III-V multi-Junction tandem cells or high multiple exciton generation nanoparticles with tunable optical gaps) or cheaper thin film technologies such as the $\mathrm{Cu}_{2} \mathrm{ZnSn}(\mathrm{S}, \mathrm{Se})_{4}$ (CZTS) quaternary semiconductor compound which has similar properties as CdTe and CIGS! [27-37]

\section{Fast SE-mapping by expanded beam ellipsometry}

The highest efficiencies measured on laboratory-sized thin film solar cells are generally well ahead of the best production module efficiencies. Thus, in photovoltaic (PV) production for commercialization many key problems are related to scale-up. The difference is primarily caused by fluctuations in area uniformity of properties caused by the individual processing steps. The primary problem with many mapping probes [e.g., single-spot spectroscopic ellipsometry (SE), Kelvin probe, laser beam induced currents (LBIC), etc.] is their reduced utility due to the long measurement time that makes in-line mapping impossible. We developed and (in this work) we demonstrate a high-speed and high-resolution measurement method to monitor the thin film PV process in-line over large areas. 
Ellipsometry determines angle-of-incidence dependent relative amplitude ratios and phase difference shifts upon specular reflection of light from a planar surface. Thus, collimated light beams are conventionally used with a well defined angle of incidence at the reflecting surface. Here we present an ellipsometric method fundamentally different from the conventional techniques [38-42]. In our instrument, the sample is illuminated by an almost diffuse, "divergent beam" of light, providing a collection of rays with diverse angles of incidence at every point of the sample. Precise "angle-selection" is performed on the detector side by a pin-hole camera. The pin-hole works as an "angle-of-incidence filter", selecting only one single light-beam from every direction (or sample position). The angular resolution of this type of camera is dependent on the diameter of the pin-hole. In the case of a single wavelength measurement, this instrument solution is appropriate for measuring a large area sample with possible non-uniform properties such that the pinhole camera selects a single angle of incidence corresponding to each sample point, but that angle varies across the sample. If the sample is moved parallel to its surface along a line during the measurement, however, each sample point will experience multiple angles of incidence successively, which provides additional information to assist in data analysis. By repeating the measurement with light of various wavelengths, multi-angle, multi-wavelength (but not continuous spectroscopic) ellipsometry data can be acquired; see ref. [39, 40].

By confining the number of measured sample points to a narrow range along a line only, we can generate continuous spectroscopic data at each point along the line image using white light illumination with a spectral dispersion (grating) after the pin-hole. This instrument produces spatial information in one dimension of the CCD array simultaneously with spectroscopic information in the perpendicular direction of the array; see Fig. 1. Both ellipsometric approaches (multi-angle/multi-wavelength and continuous spectroscopic) are useful, for example, in the analysis of product moving along a coating line.

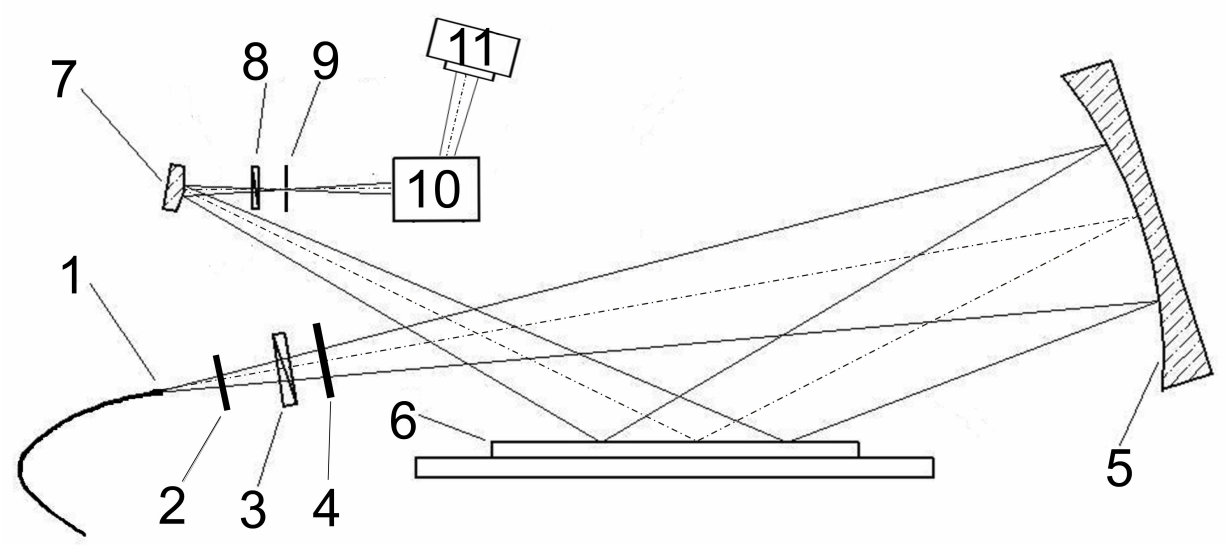

Figure 1: (1) "white" light source, (2) narrow, rectangular aperture, (3) film-polarizer, (4) compensator, (5) spherical mirror (6) sample, (7) cylindrical mirror, corrected beam, (8) analyzer, (9) pinhole, (10) correction-dispersion optics, (11) CCD detector array.

Instrumentation 

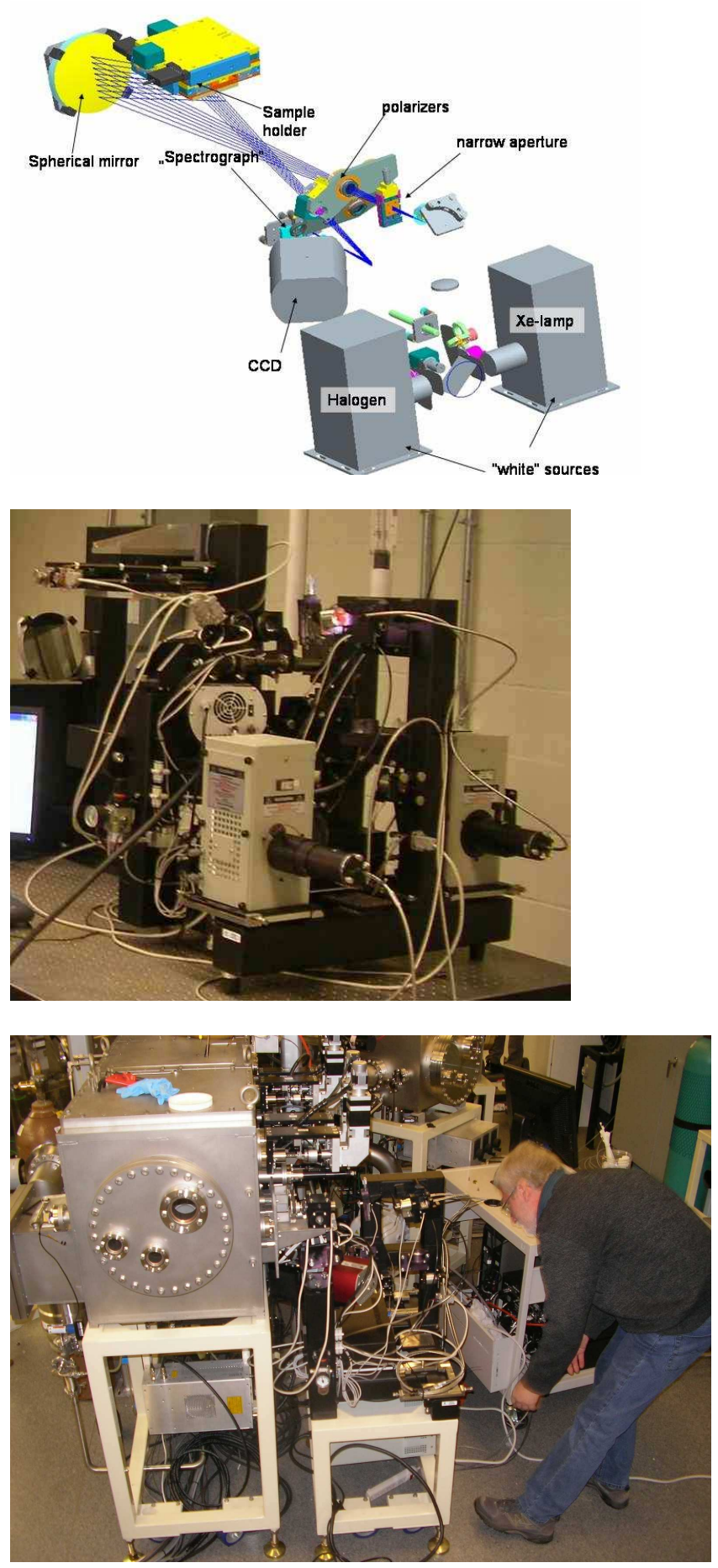

Figure 2 The prototype CAD-drawing (upper), located within the Center for Photovoltaics Innovation and Commercialization at the University of Toledo (Ohio), earlier operating in an ex situ mode (middle), presently integrated into a multichamber cluster tool for in situ analysis (bottom).

A near-ultraviolet-to-visible (nuv-vis) range $(350-630 \mathrm{~nm}$ ) of the first generation divergent beam instrument [41, 42] were built in MFA, Budapest, but this prototype limits potential photovoltaics applications; as a result, an extension into the near-infrared (NIR) region were performed to probe below the band gap of absorber layers in order to measure their thicknesses (Fig. 2). Thus, with a broadened spectral range, it became possible to characterize a wider variety of layers and structures. Divergent beam ellipsometers (using uncollimated beam) employ film polarizers, which exhibit a wide semi-field angle but limited spectral range. In earlier state, dual spectral range capability was a convenient solution whereby the optical elements (source, polarizer-analyzer pairs, and optical grating) were automatically interchangeable, and the entire nuv-nir (350-1000 nm) spectra for a line image was detectable in two measurement cycles with one CCD camera [42], see Fig. 2. 
Calibrations of the angle of incidence (relationship of pixel number to angle) and the mirror effects are performed via well-known and optimized structures, in this case three $\mathrm{SiO}_{2} / \mathrm{Si}$ samples with different thicknesses. Although the precision and accuracy of the instrument is not higher than that of standard step-wise wavelength scanning ellipsometers that probe a single spot, it is capable of determining the thickness of a silicon-dioxide film with sub-nanometer precision and the angle-of-incidence with sub-tenth-degree precision in the calibration process. Mirror and possible window effects are calculated using the following equation:

$$
\rho_{\mathrm{opt}}=\rho_{\text {meas }} * \rho_{\text {mirror }} \text { (different for each point and each wavelength) } \quad \text { [eq. 1] }
$$

where $\rho_{\text {opt }}$ is the measured value without mirrors and windows, $\rho_{\text {meas }}$ is the actually measured value, and $\rho_{\text {mirror }}$ is the effect of the mirrors and the windows of the chamber (if any). The actual values of $\rho_{\text {mirror }}$ are theoretically different for each sample position and each wavelength; however, these dependences are relatively weak. By calibrating with three $\mathrm{SiO}_{2} / \mathrm{Si}$ samples having different thicknesses, $3 \mathrm{~N}(\psi, \Delta)$ values are measured for each sample position (where $\mathrm{N}$ is the number of wavelengths), and $2 \mathrm{~N}+4$ unknown values must be determined by fitting for a full calibration. These include $\mathrm{N}$ pairs of $\left\{\operatorname{Re}\left(\rho_{\text {mirror }}\right), \operatorname{Im}\left(\rho_{\text {mirror }}\right)\right\}$, along with three thicknesses and one angle of incidence. The calibration can be performed independently for each pixel of the CCD; however, improved signal-to-noise is obtained by summing the irradiances according to pixel-groups, in consideration of the lateral resolution of the system. After an initial attempt, the calibration values are smoothed as a function of sample position and wavelength using second order polynomials. A smooth variation is expected for the angle of incidence and for the $\left\{\operatorname{Re}\left(\rho_{\text {mirror }}\right), \operatorname{Im}\left(\rho_{\text {mirror }}\right)\right\}$ values. As a result, smoothing of the dependence of angle of incidence on position as well as the dependence of $\rho_{\text {mirror }}$ on position and wavelength reduces errors in the calibration measurement [42].

\section{Rotating compensator multi channel mapping ellipsometry}

Rotating polarizer or analyzer measuring mode is not the optimal (especially when tan $\psi$ is high and/or $\cos \Delta$ is close to 1 or -1 . We have investigated the performance gain of rotating compensator multi channel mapping ellipsometry, too!

We used an air spaced zero-order $\mathrm{MgF}_{2}$ quarter wave retarder after the polarizer (from Karl Lambrecht Co.) with an equivalent rotating mechanism as is used with the analyzer and polarizer. After careful calibration (most part of the beam is going through at non-normal direction through the compensator) we have the angle of incidences, the mirror-(window)-corrections and the $\delta$-shift by the retarder at all sample(-CCD)-points. (Details are in the article by C. Major et al. ibid [43]) 

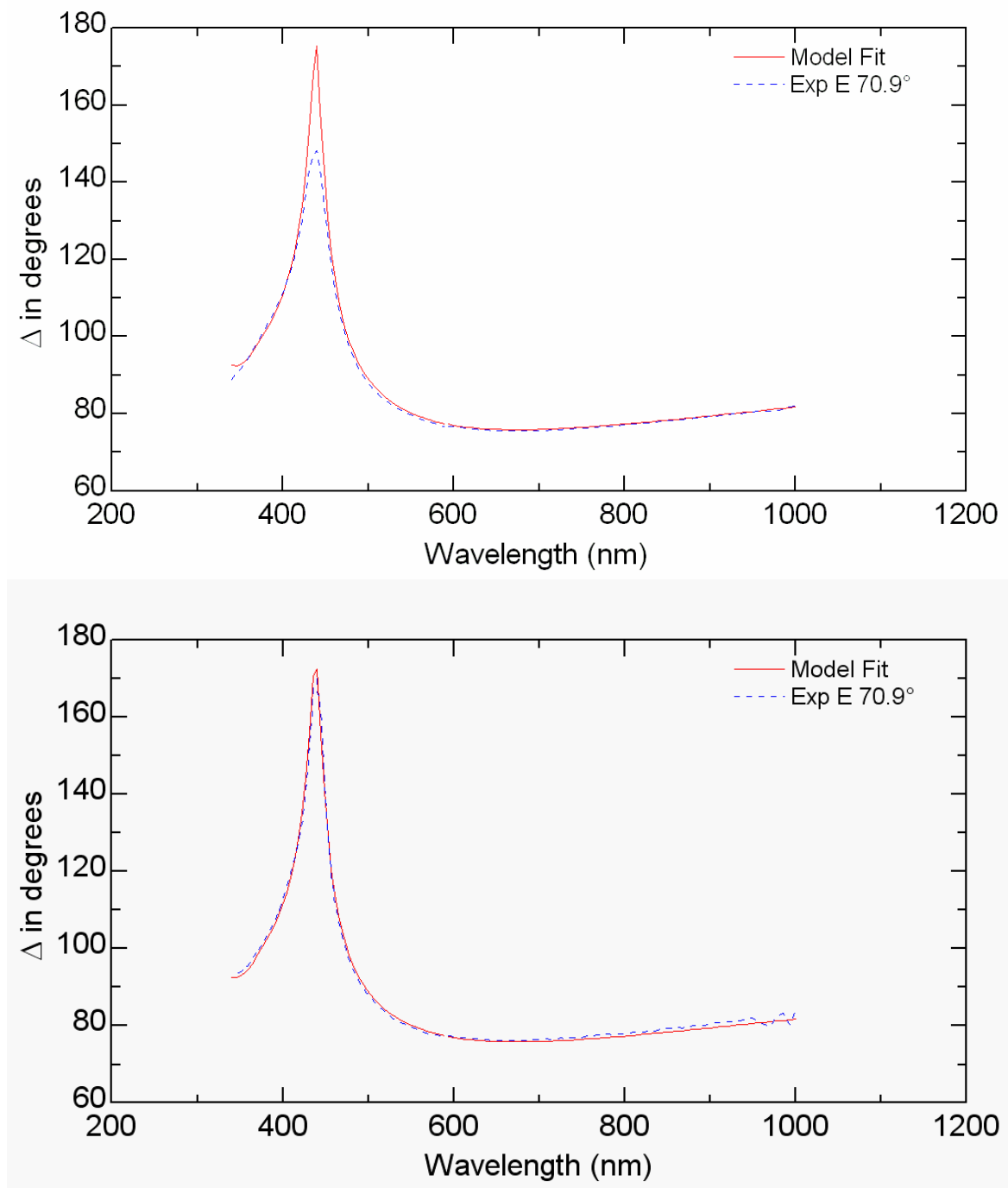

Figure $3100 \mathrm{~nm}$ oxide: $\Delta$ is near $180 \mathrm{deg}$. Comparison of rotating Polarizer (left) and rotating Compensator (right) measurements 

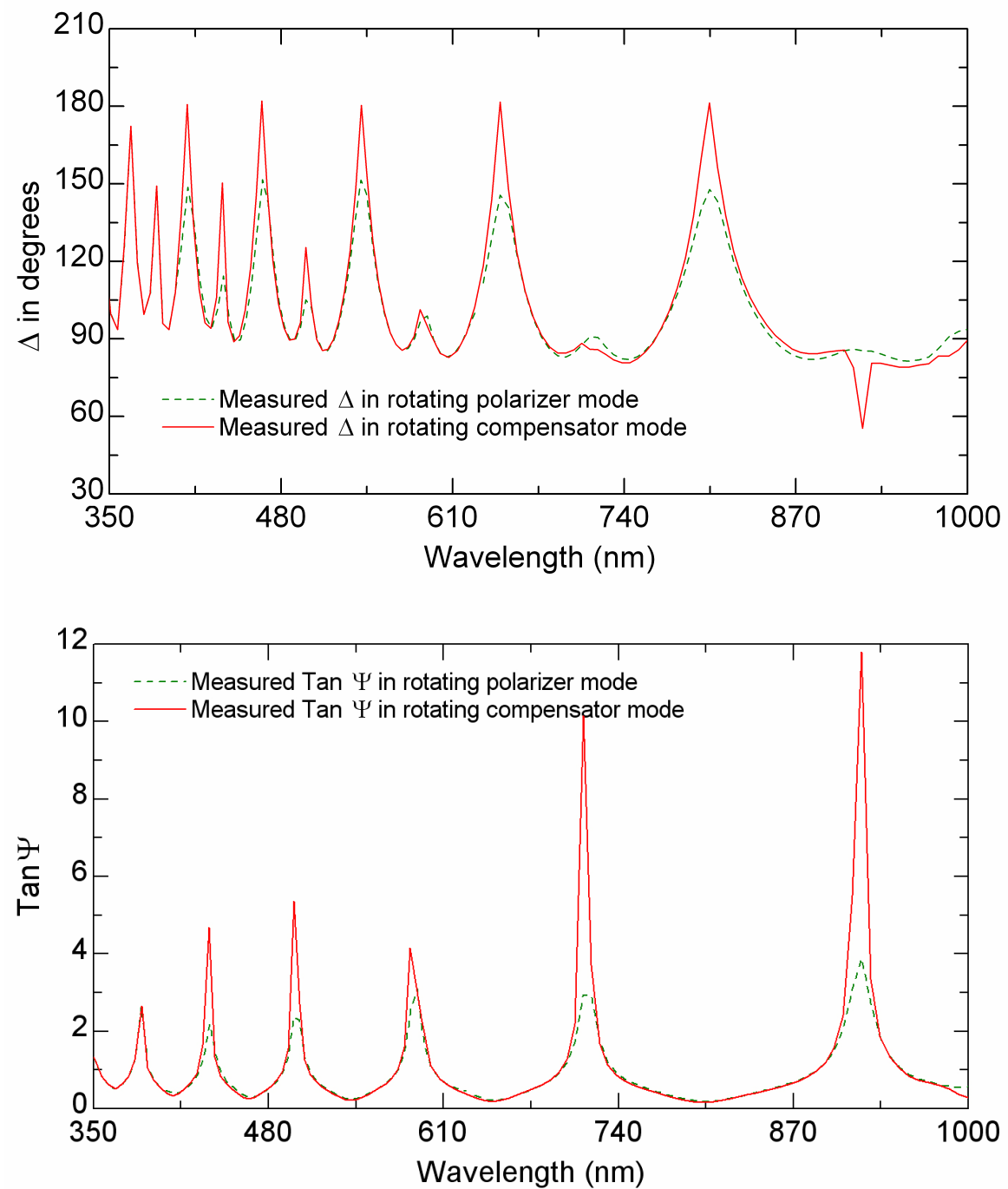

Figure 4 Comparison of rotating Polarizer and rotating Compensator measurement (nominally $1450 \mathrm{~nm}$ thick oxide layer) 

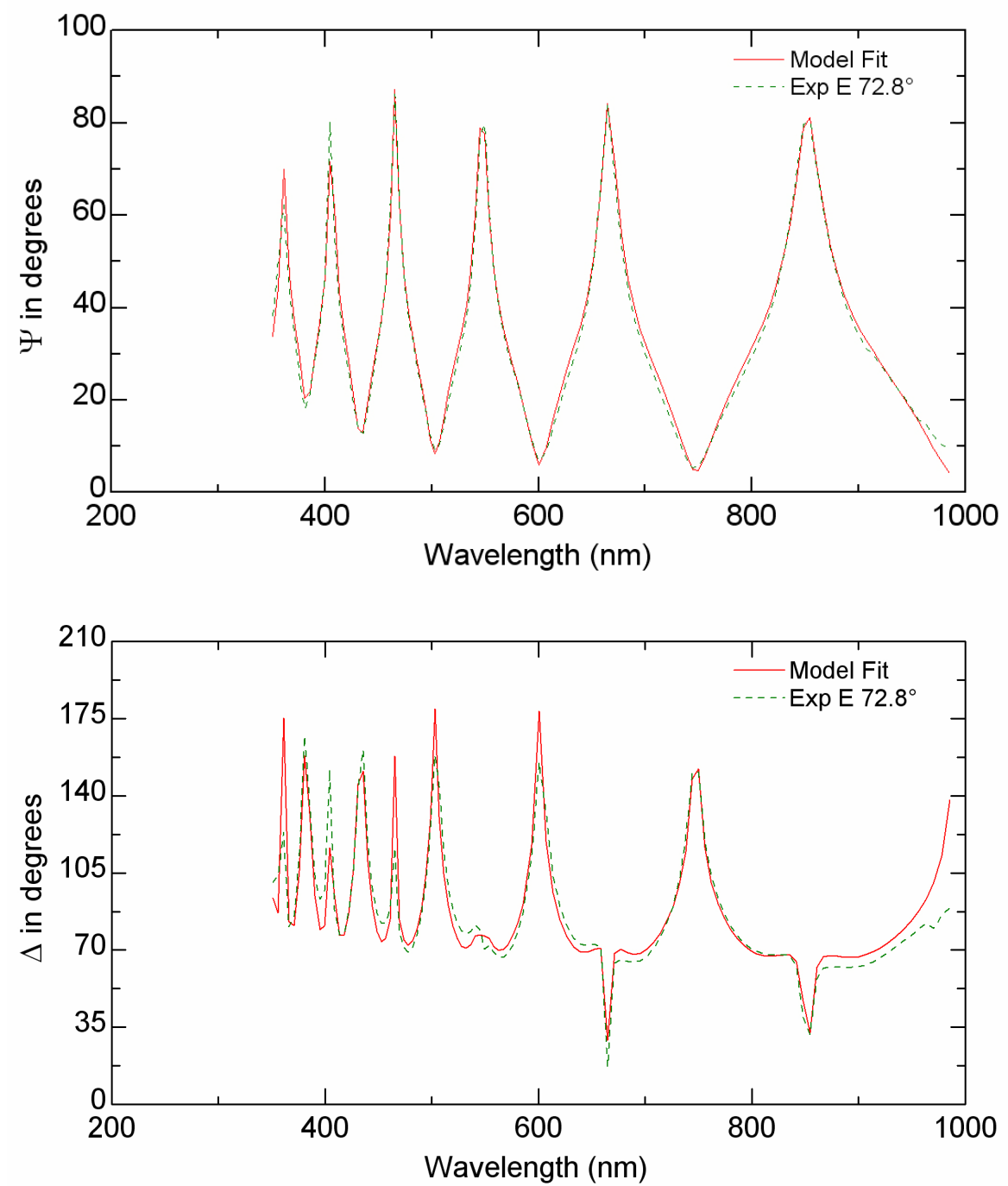

Figure 5 Fit of rotating Compensator measurement (nominally $1350 \mathrm{~nm}$ thick oxide layer)

\section{Demonstration sample preparations}

Thermal oxide layers on 6-inch $\mathrm{Si}$-wafers were prepared in usual furnace for calibrating and validating measurements. Poly-Si layer on $\mathrm{SiO}_{2}$ on 6-inch Si-wafer (poly-Si 46) were prepared by LPCVD.

$\mathrm{ZnO}$ layer were deposited by magnetron sputtering onto Ag-covered plastic foil in a cassette roll-to-roll model machine.

Hydrogenated amorphous silicon (a-Si:H), nanocrystalline silicon (nc-Si:H), and mixed phase layers were deposited by very high frequency plasma enhanced chemical vapor deposition (vhf PECVD) onto $\sim 15$ x 15 $\mathrm{cm}^{2}$ soda lime glass (SLG) and $\sim 5 \times \mathrm{cm}^{2} \mathrm{Si}$ wafer substrates. A thin Cr layer was sputtered onto the SLG prior the $\mathrm{Si}: \mathrm{H}$ layer deposition to ensure adhesion and form a standard reflective interface for further SE measurement. The $5 \times 30 \mathrm{~cm}^{2} \mathrm{Cr}$ target was located at a distance of $7 \mathrm{~cm}$ from the substrate. The sputtering in all cases was performed for 40 minutes with 5 mTorr Ar gas and at $40 \mathrm{~W}$ rf power. The parallel depositions on $5 \mathrm{~cm} \mathrm{Si}$ wafer substrates were carried out with the same parameters in order to study the layers by cross sectional transmission electron microscopy (XTEM).

The deposition conditions for the Si:H films studied here are summarized in Table 1. The vhf PECVD electrode size is approximately $15 \times 15 \mathrm{~cm}^{2}$, and the applied vhf frequency was $70 \mathrm{MHz}$. Prior to deposition all 
substrates were preheated to a temperate of $200{ }^{\circ} \mathrm{C}$. The measured samples were deposited as part of an ongoing program for tandem a-Si:H/nc-Si:H silicon solar cell development. In the case of these solar materials, analyses of the processes for phase evolution and uniformity are crucial. XTEM images are shown for two such films in Fig. 6. The film prepared with $\mathrm{R}=20$ (left) evolves from a-Si:H through mixed-phase $\mathrm{Si}: \mathrm{H}$ to nc-Si:H; the film prepared with $\mathrm{R}=50$ (right) nucleates immediately from the substrate as nc-Si:H. ( $R$ is the ratio of the $\mathrm{H}_{2}$ and the $\mathrm{SiH}_{4}$, see Table 1.).
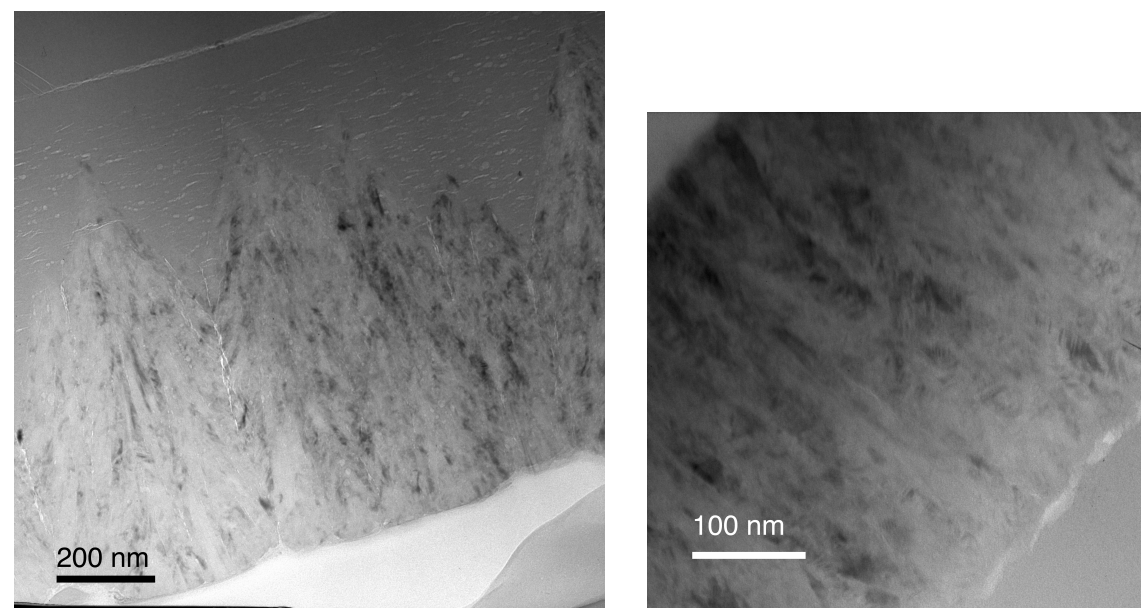

Figure 6: XTEM images for a sample prepared at $R=20$ (left; MCS 25) and one prepared at $R=50$ (right; MCS 26). The substrate is seen in the upper-left corner. The a-Si:H, mixed-phase (a-Si:H + nc-Si:H), and nc-Si:H sub-layers can be seen in the $R=20$ sample from the upper to lower part of the image.

Table 1 Deposition parameters of the Si:H samples prepared onto Si wafer and Cr-coated SLG substrates.

\begin{tabular}{|c|c|c|c|c|c|c|}
\hline Sample no. & $\begin{array}{c}\text { Time } \\
{[\mathrm{min}]}\end{array}$ & $\begin{array}{c}\text { Pressure } \\
{[\mathrm{mT} \text { Torr }]}\end{array}$ & $\begin{array}{c}\text { RF power } \\
{[\mathrm{W}]}\end{array}$ & $\begin{array}{c}\mathrm{SiH}_{4} \\
{[\mathrm{sccm}]}\end{array}$ & $\begin{array}{c}\mathrm{H}_{2} \\
{[\mathrm{sccm}]}\end{array}$ & $\begin{array}{c}R \\
\left(\mathrm{H}_{2} / \mathrm{SiH}_{4}\right)\end{array}$ \\
\hline MCS 23 & 10 & 300 & 4 & 10 & 5 & 0.5 \\
\hline MCS 25 & 20 & 1500 & 40 & 5 & 100 & 20 \\
\hline MCS 26 & 20 & 1500 & 40 & 5 & 250 & 50 \\
\hline
\end{tabular}

The thin films were measured during deposition in-situ and in real-time using a rotating-compensator multichannel spectroscopic ellipsometer (J.A. Woollam Co., M-2000DI) at one point close to the center of the $15 \times 15 \mathrm{~cm}^{2}$ sample. The single-spot measurements of a series of ellipsometric spectra obtained versus time during deposition permit the development of an appropriate multilayer optical model, which provides starting parameters in least-squares regression for the analysis of the mapping data acquired by our newly developed prototype spectroscopic ellipsometer for imaging/mapping purposes.

The polycrystalline CdS and CdTe thin films were magnetron sputtered onto $\sim 10 \mathrm{x} 15 \mathrm{~cm}^{2}$ Mo-covered soda lime glass (SLG/Mo/CdTe/CdS) [44]

The thin films were measured during deposition in-situ and in real-time using a rotating-compensator multichannel spectroscopic ellipsometer (J.A. Woollam Co., M-2000DI) at one point close to the center of the samples. The single-spot measurements of a series of ellipsometric spectra obtained versus time during deposition permit the development of an appropriate multilayer optical model, which provides starting parameters in least-squares regression for the analysis of the mapping data acquired by our newly developed 
prototype spectroscopic ellipsometer for imaging/mapping purposes. To check our mapping expanded beam SE results, we performed mapping SE measurements and evaluations (using the same optical models and wavelength regions) by an AccuMap device by J.A. Woollam Co.

\section{RESULTS AND DISCUSSION}

The dual-spectral prototype were designed to enable in situ imaging/mapping within one of the chambers of a cluster tool at the Center for Photovoltaics Innovation and Commercialization (PVIC); University of Toledo (Ohio), see Fig. 2.

\section{Calibration and validating measurements}

Calibration and validating measurements were performed on nominally 20, 40, 60 and $80 \mathrm{~nm}$ thermal oxide covered 6-inch Si-wafers. The results were compared with AccuMap results, see Figure 7.
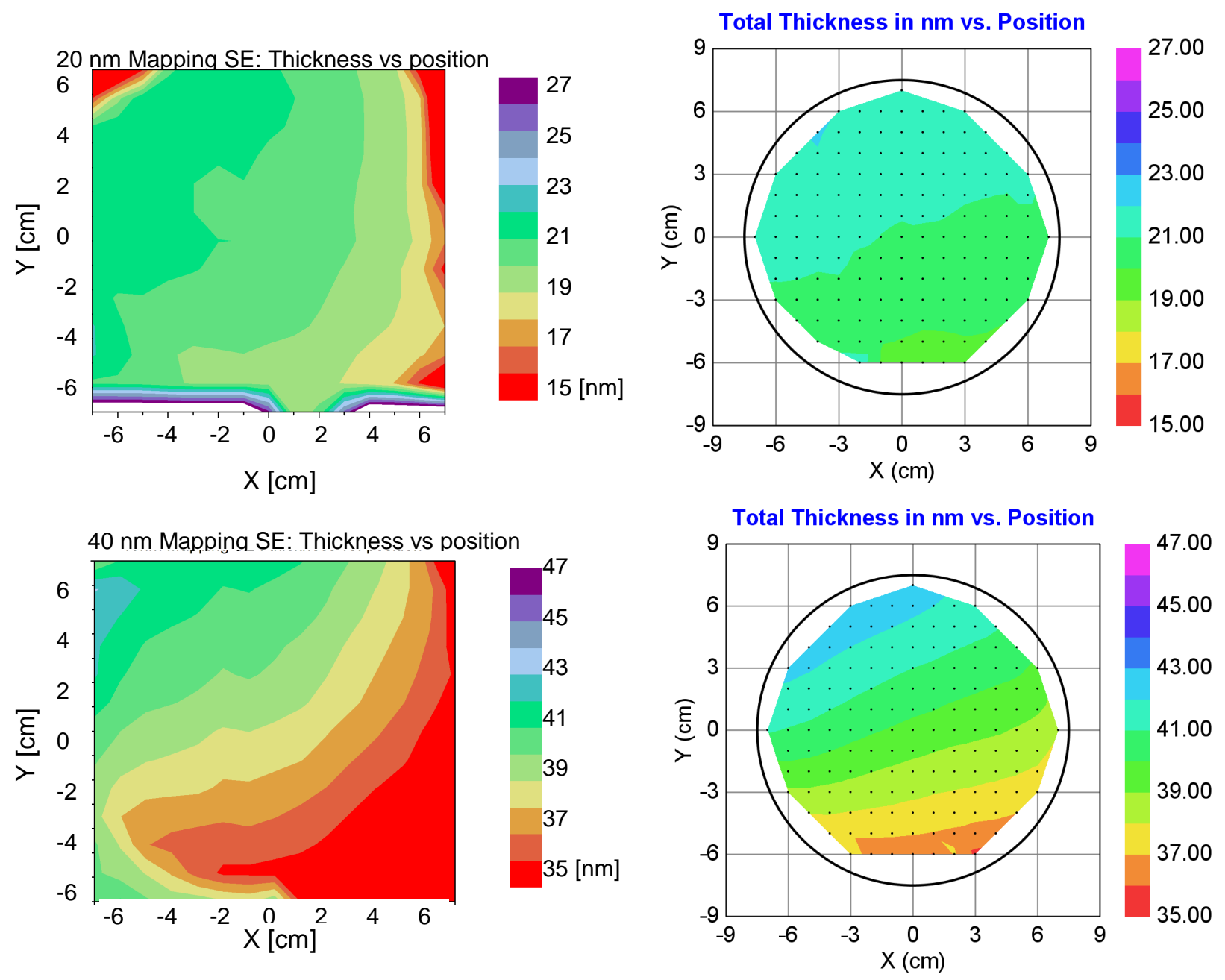

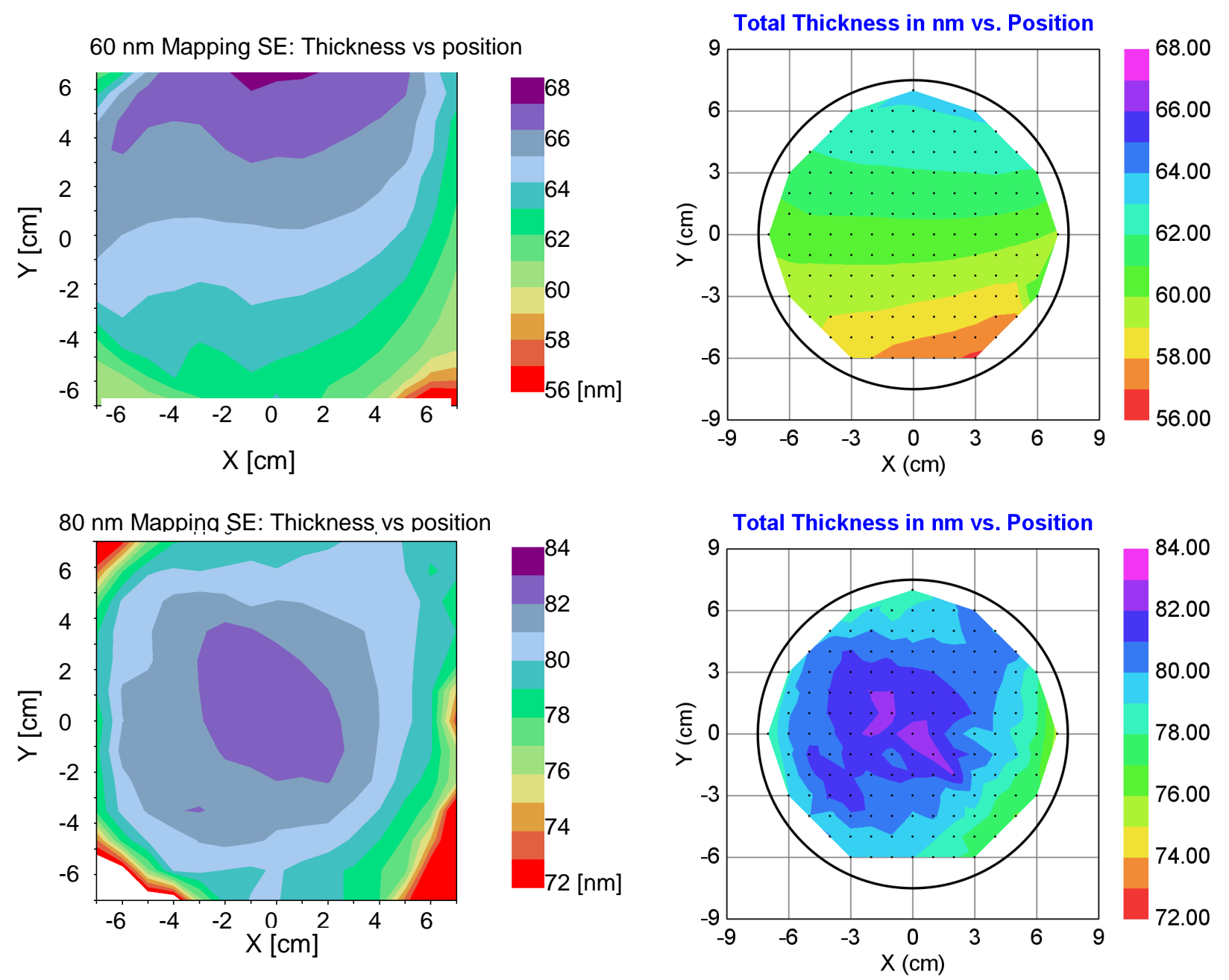

Figure 7 Calibrating and validating measurements on thermal oxides (nominal thickness: 20, 40, 60 and $80 \mathrm{~nm}$ ) (differences between expanded beam (left) and AccuMap (right) $\leq 1 \mathrm{~nm}$ ) Only the center line is used for calibration, the other points considered as checking. Points at the corners are from spectra measured on partly the sample and mainly on the holder.
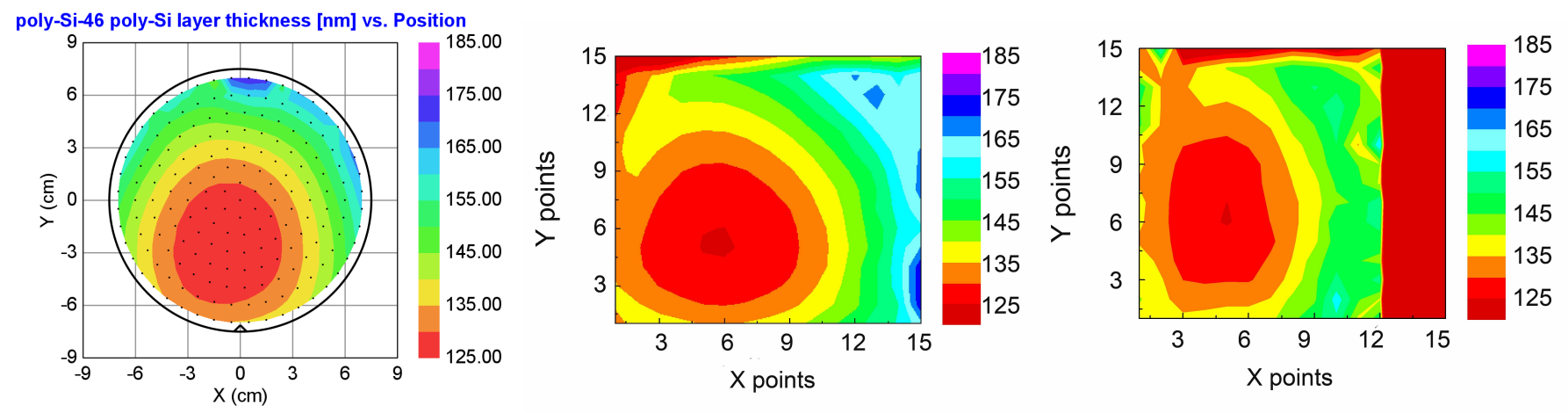


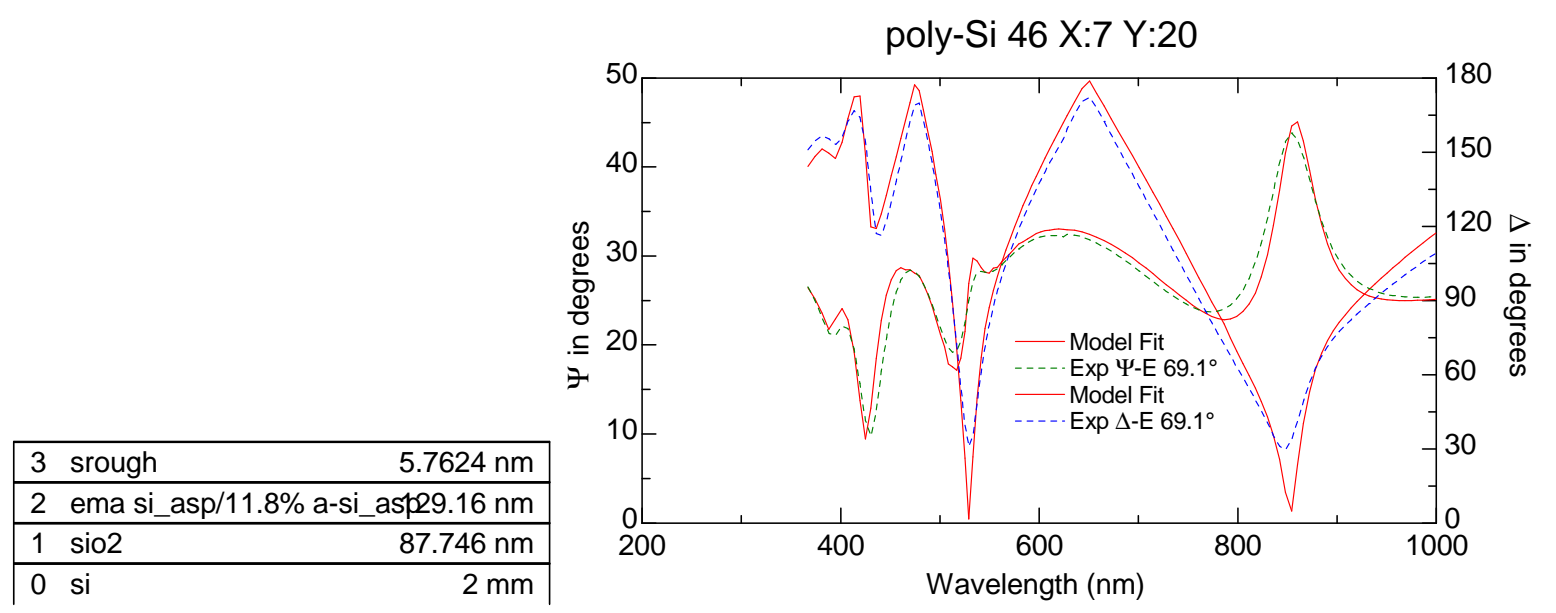

Figure 8 Thickness-map of poly-Si layer on $\mathrm{SiO}_{2}$ on 6-inch Si-wafer by AccuMap (top left), desk-top expanded beam device line-by-line (stop during measurement, top middle) and expanded beam device line-by-line during continuous moving, respectively (top-right). The used optical model (effective medium approximation with c-Si/a-Si mixture) and a sample spectrum-pair (with model fit) from a central sample-position is shown in the bottom row. Measured ellipsometric spectra shown in the bottom row are from the continuously moving/mapping.

\section{Demonstration measurements}

\section{Silicon layers}

Poly-Si layer (poly-Si 46) on $\mathrm{SiO}_{2}$ on 6-inch Si-wafer (prepared by LPCVD) were measured by AccuMap and expanded beam device line-by-line $(1 \mathrm{X}$-point $=1 \mathrm{~cm})$ and during continuous moving $(1 \mathrm{X}$-point $\sim 1.5 \mathrm{~cm})$. The calculated thickness-maps are shown in Fig. 8 and a very good agreement can be established.

Demonstration mapping measurements have been performed ex situ on mixed-phase $(\mathrm{a}-\mathrm{Si}: \mathrm{H}+\mathrm{nc}-\mathrm{Si}: \mathrm{H})$ silicon films having the structure: $\mathrm{nc}-\mathrm{Si} /(\mathrm{nc}-\mathrm{Si}+\mathrm{a}-\mathrm{Si}) / \mathrm{a}-\mathrm{Si} / \mathrm{Cr} / \mathrm{glass}$. Imaging/mapping for initial demonstration purposes, however, was performed on a single phase a-Si:H/Cr/glass sample (see Fig. 9) and compared with independent mapping measurements made by a commercially-available instrument (AccuMap) that is capable of point-by-point mapping measurements on larger size samples. With intentionally extreme settings of the deposition parameters, a purely amorphous layer with high spatial non-uniformity was prepared in order to demonstrate the utility of our method. A relatively simple optical model was used to analyze the mapping measurement: opaque $\mathrm{Cr}$ as a substrate, and a-Si:H with a Tauc-Lorentz oscillator dispersion model. The parameters of the Tauc-Lorentz oscillator were taken from the real time SE measurement. 


\section{AccuMap MCS-23}

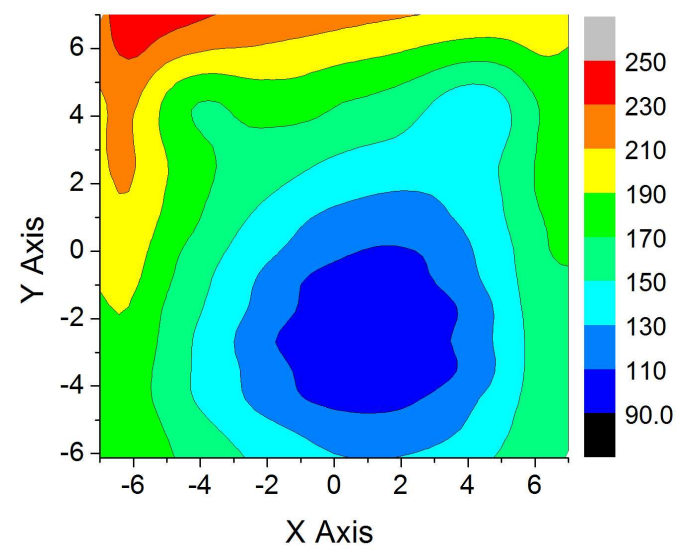

\section{thickness map [nm]}

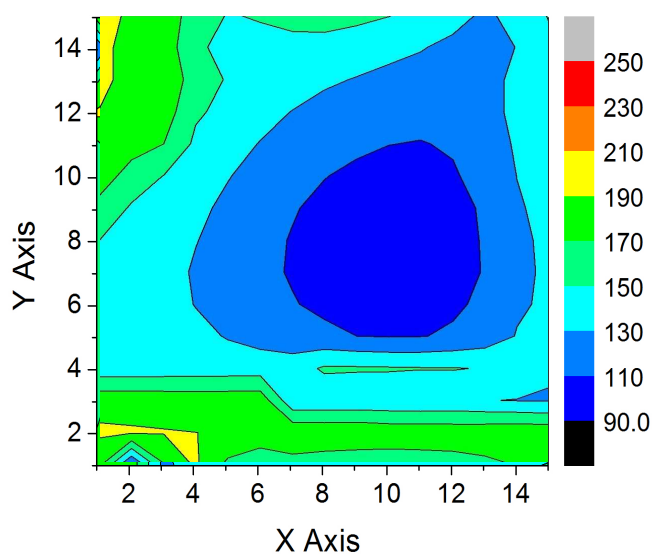

Figure 9 Mapping with a commercial instrument (left) and imaging/mapping with an expanded beam instrument (right) showing reasonable agreement; thickness maps in $\mathrm{nm}$ were obtained for a $15 \times 15 \mathrm{~cm}^{2}$ size sample of single-phase hydrogenated amorphous silicon (a-Si:H) layer on Cr. The map generated by the commercial instrument denotes points on a square grid at the sample surface; the map generated by the expanded-beam ellipsometer is described in terms of pixel-group coordinates.

We performed the second evaluation of the mapping measurement using the $\mathrm{R}=20$ sample of Table 1 (see Fig. 10) and applying a 3-layer optical model consisting of the following stack: nc-Si:H/(a-Si:H+nc-Si:H)/a$\mathrm{Si}: \mathrm{H} / \mathrm{Cr}$, which was developed from single-spot, real-time spectroscopic ellipsometry (SE) analysis [45]. In addition to the appropriate model, this real time SE measurement also provided good starting parameters in least-squares regression for the analysis of the mapping data using the model. We also compared our mapping results with the results (using the same optical model) of independently performed ex-situ measurements with the AccuMap (see Fig. 10). We must note that this latter instrument obtains ellipsometric spectra at mm-size spots on a square grid, whereas the expanded-beam instrument obtains spectra for $\sim 5 \mathrm{x} 5 \mathrm{~mm}_{2}$ areas. So, we cannot ensure that the individual ellipsometers are collecting spectra from precisely the same areas with the same resolution.

The agreement in Fig. 10 is very good, considering the complexity of the model, consisting of three individual Si:H layers. The circular areas of reduced thickness on the maps arise from the use of a top cathode plate with two holes that permit passage of the beam for real time SE. When larger area devices are made, these specialized electrodes are replaced with standard ones. 


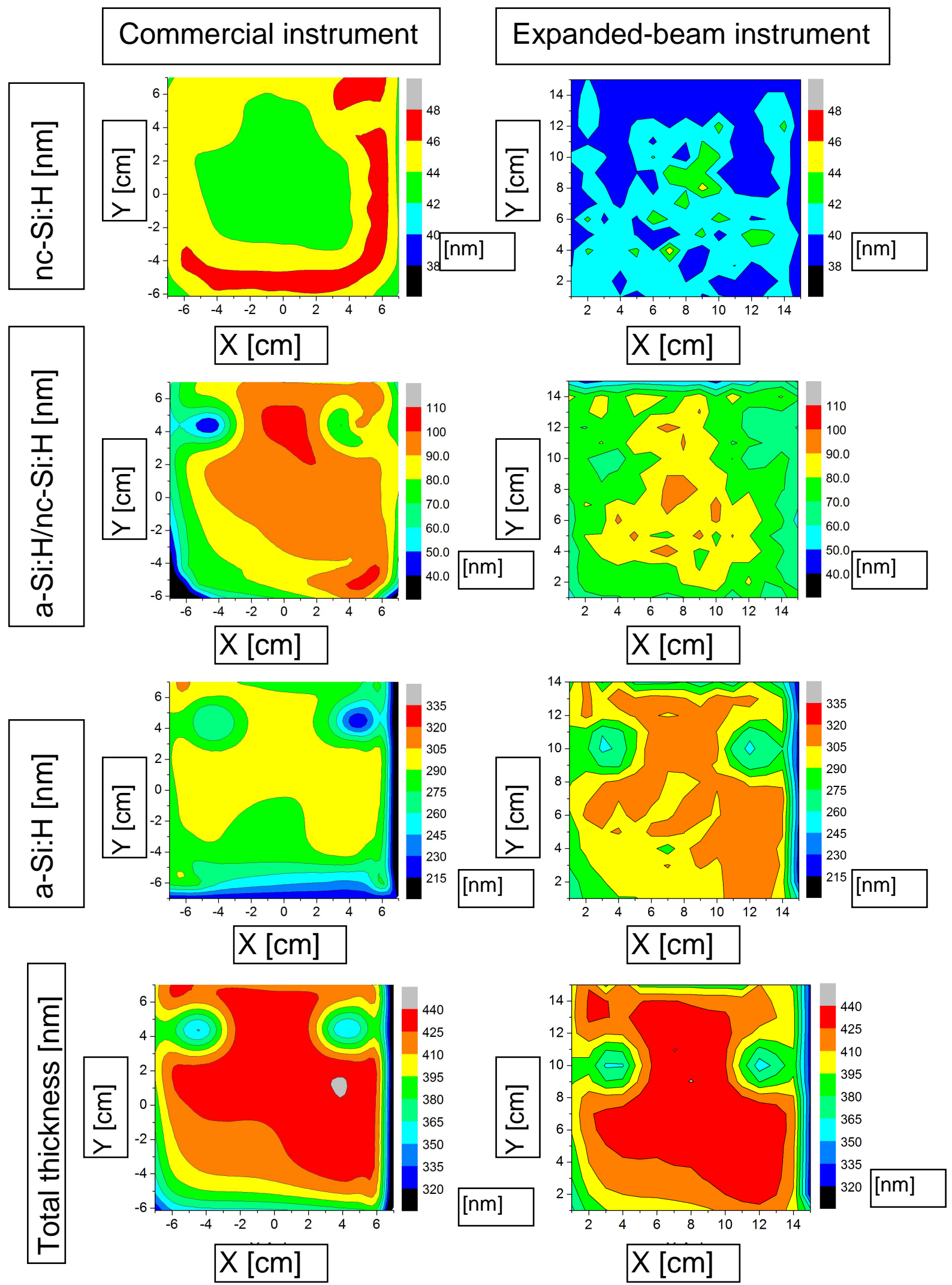

Figure 10 Mapping with a commercial instrument and imaging/mapping with the expanded-beam instrument for an thin Si:H film with R=20 using the 3-layer optical model given by nc-Si:H/(a-Si:H+nc-Si:H)/a-Si:H/Cr. The total thickness is the sum of the thicknesses of the three sub-layers for each spatial point. 

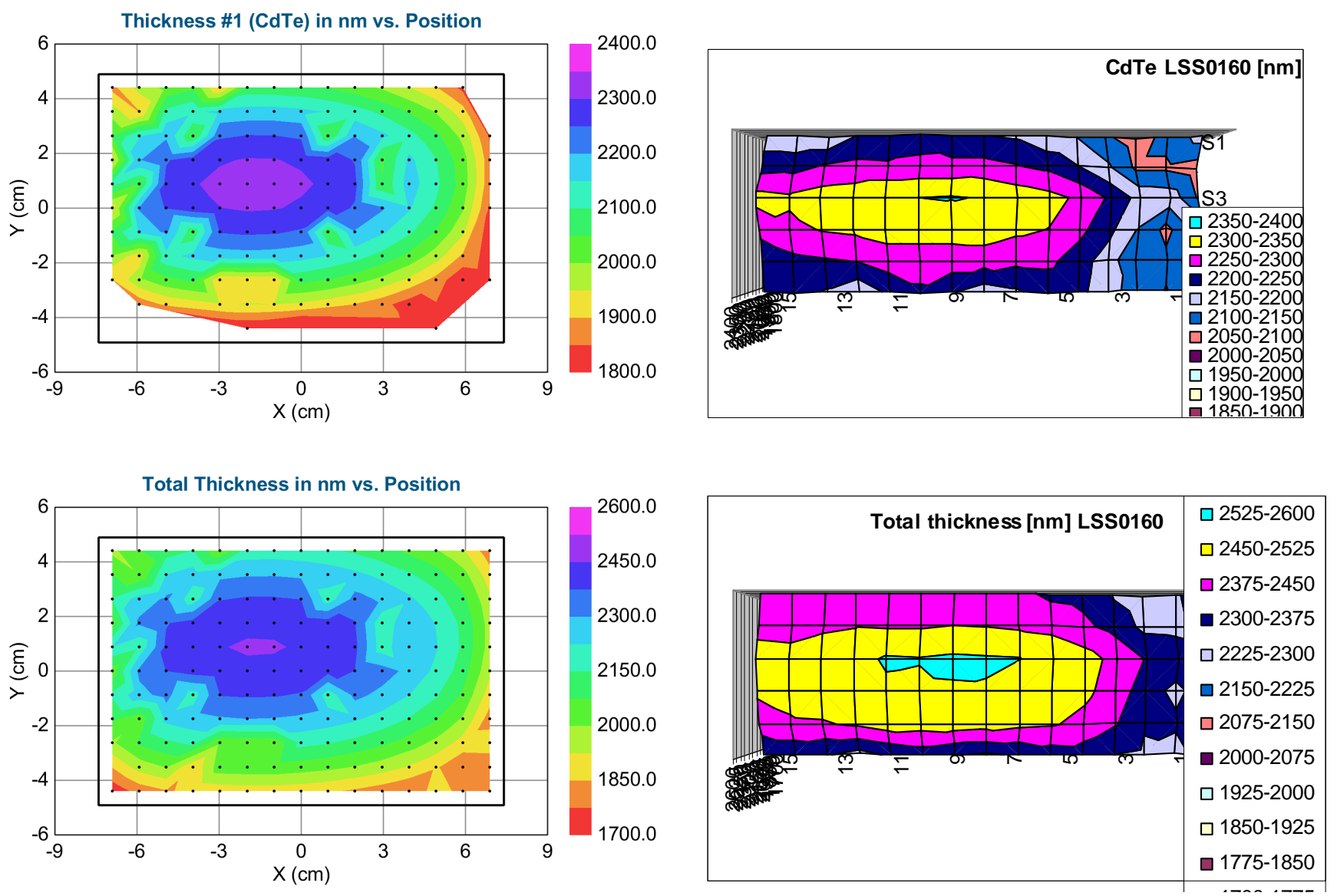

Figure 11 Mapping with the AccuMap (left) and imaging/mapping with the expanded-beam instrument (right) for a $S L G / M o / C d T e / C d S$ sample. The total thickness is the sum of the thicknesses including the surface roughness and interface layers for each spatial point.

The magnetron sputtered polycrystalline $\mathrm{CdS}$ and $\mathrm{CdTe}$ thin films were modelled by dielectric functions taken from real time SE measurement and the model contained surface roughness and interface layers, too. We show only the thickness of the CdTe layer and the "Total thickness" (all layers in the models, including the surface roughness and interface layers) in Fig. 11. Unfortunately, we had a problem with the sample holder (because of the continuous changing of the rigid sample holders and the cassette roll-to-roll model machine) so we could measure only the central part of the sample by the imaging instrument.

One remark: if the lateral change (inhomogeneity) is well over $1 \mathrm{~nm} / \mathrm{mm}$ then the expanded beam ellipsometer does not measure the same thing as single spot ellipsometers! In the case of $80 \mathrm{~nm}$ thick $\mathrm{SiO}_{2}$ film the inhomogeneity is: $6 \mathrm{~nm} / 6 \mathrm{~cm}=0.1 \mathrm{~nm} / \mathrm{mm}$, so the inhomogeneity within the expanded beam SE's elementary area is $0.5 \mathrm{~nm}$. In the case of the polysilicon sample the inhomogeneity is $50 \mathrm{~nm} / 6 \mathrm{~cm}=0.8 \mathrm{~nm} / \mathrm{mm}$, so the inhomogeneity within the expanded beam SE's elementary area is $4 \mathrm{~nm}$. In the case of the CdTe/CdS sample the inhomogeneity is $300 \mathrm{~nm} / 4 \mathrm{~cm}=7.5 \mathrm{~nm} / \mathrm{mm}$, so the inhomogeneity within the expanded beam SE's elementary area is $\underline{40 \mathrm{~nm}}$ ! However, the difference between the mapping results is below $1 \%$ in all cases.

\section{In-line roll-to-roll (RtR) measurement}

We measured a $\mathrm{ZnO}$ layer (deposited by magnetron sputtering onto an Ag-covered plastic foil in a cassette roll-to-roll model machine) in-line by the expanded beam device, see Fig. 12. We used a simple Cauchydispersion for the $\mathrm{ZnO}$ layer because of the limited wavelength region, see the selected spectra (measured and fitted) in Fig. 12. Note the larger MSE values at the edges of the sample! 

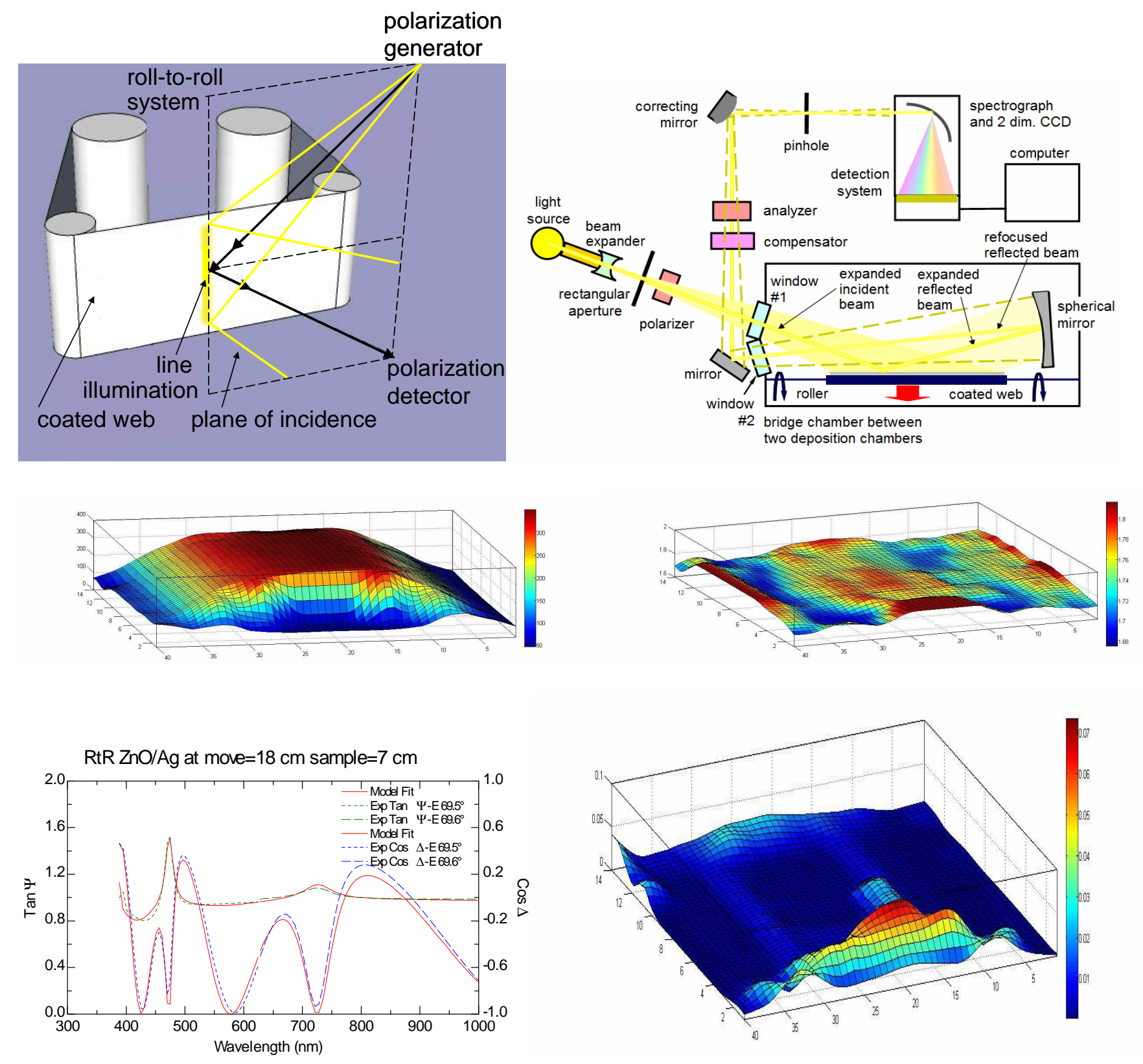

Figure $12 \mathrm{ZnO}$ layer (deposited by magnetron sputtering onto Ag-covered plastic foil in a cassette roll-to-roll model machine) measured in-line by the expanded beam device. (Upper part) The horizontal axis is the direction of web advance. Mapping SE was performed from the leading end of the roll. The vertical axis is the width of the web, from which the edge-to-edge uniformity of the film deposition is evaluated. The gradient at the starting and ending parts is due to the $\sin \Theta / r^{2}$ dependence of the flux. Thickness-map (middle, left), An-map (middle, right), MSE-map (bottom, right) Result of the selected (1 elementary point) expanded beam mapping SE measurement: MSE $=0.059$, Thickness $=326.6 \pm 8$ $n m, A n=1.80 \pm 0.03, B n=-0.003 \pm 0.0047, C n=0.007 \pm 0.0007, A k=0.017 \pm 0.007, B k=1.44 \pm 0.6$ (bottom, left)

In another experiment, we measured first a $\mathrm{ZnO}$ only (on Ag layer/plastic foil) RtR sample and moved the cassette roll-to-roll model machine into the a-Si deposition chamber. After the a-Si deposition the cassette rollto-roll model machine was moved back to the measuring chamber (without breaking the vacuum) and measured again by the expanded beam mapping SE, see Fig. 13. Mapping SE was performed from the leading end of the roll, counter-clockwise (CCW) first and clockwise (CW) after the a-Si deposition. We have got the same map for the $\mathrm{ZnO}$ layer and we can see the same greater MSE values at the "wrinkled" line of the foil! This "wrinkle" cause a similar effect as the edges of the foil, possibly making the angles of incidence locally different from the calibrated ones. This effect shows that our expanded beam mapping SE is a robust device which is relatively insensitive for the small distortions. 

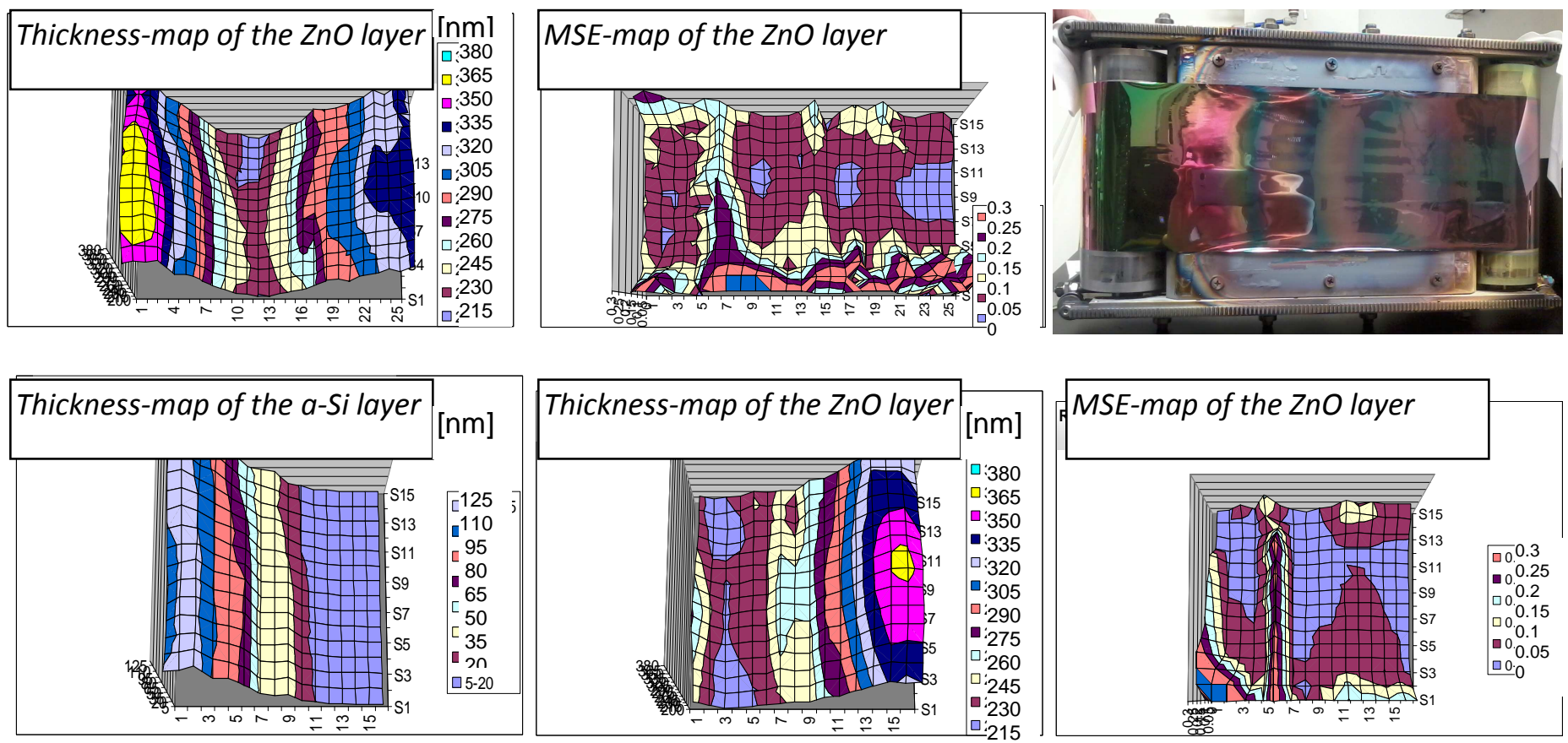

Figure 13 Thickness-map (upper-left) and MSE-map (upper-center) of the ZnO layer (deposited by magnetron sputtering onto Ag-covered plastic foil in a cassette roll-to-roll model machine, upper-right) and Thickness-map (bottom-left) of a-Si layer and Thickness-map (bottom-left) of ZnO layer and MSE-map (bottom-right). The a-Si layer was deposited after the first measurement. Measurements were performed in-line by the expanded beam device. The horizontal axis is the direction of web advance (in cm steps). Mapping SE was performed from the leading end of the roll, counter-clockwise (CCW) first and clockwise (CW) after the a-Si deposition. Note, the greater MSE values at the "wrinkled" line of the foil!

Present status and near future plans

The dual-spectral prototype (enhanced with a rotating compensator option) is working as an in situ imaging/mapping device (currently a single 40 point line image can be collected in $10 \mathrm{sec}$ over a $15 \mathrm{~cm}$ width of PV material) within one of the chambers of a cluster tool at the Center for Photovoltaics Innovation and Commercialization (PVIC) University of Toledo (Ohio)

Currently, a single-spectrum (350-1000 nm, with a rotating compensator) instrument for 30-cm sample-size is completed at MFA (Budapest, Hungary) and it is under calibration. (See Fig. 14) Our group is involved in a domestic project (supported by the Hungarian Government) in consortium with a Hungarian company (Tenzi Ltd.). Our goal is to develop prototypes of expanded beam ellipsometers for applications in solar cell industry, and in the next 2 years (2013-2014) we plan to fabricate prototypes for 60-cm (end of 2013) and 90-cm samplesize (2014). These instruments will measure the single-spectrum (350-1000 nm) within $5 \mathrm{sec}$. 


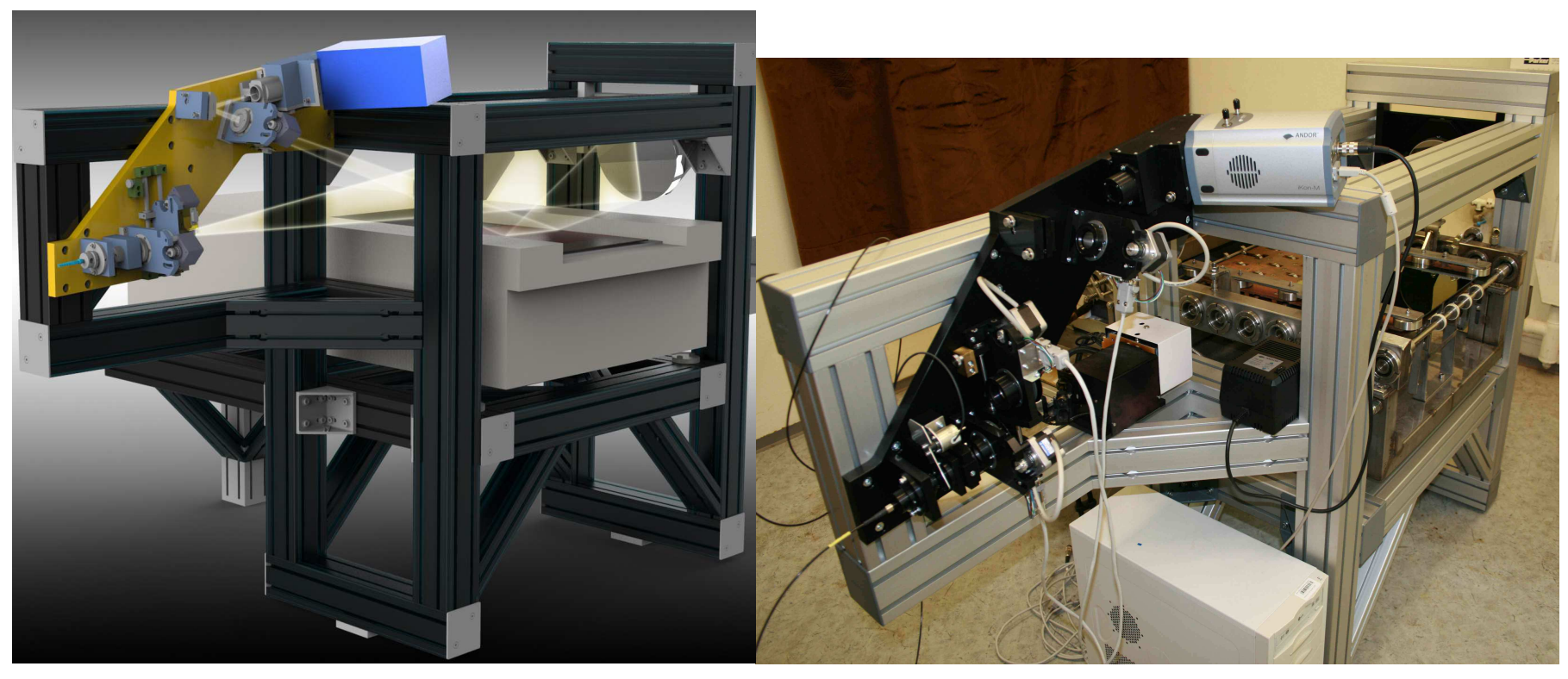

Figure 14 Single-spectrum (350-1000 nm), rotating compensator expanded beam SE mapping device for 30-cm samplesize is completed at MFA (Budapest, Hungary); CAD-drawing with the beam-path (left) and photograph (right)

\section{CONCLUSIONS}

Thin film PV is more cost effective than bulk PV technology, but higher efficiency needs lateral homogeneity! Commercial instruments using 1D detector arrays for spectroscopic ellipsometry must translate either the sample or the ellipsometer in two dimensions in order to map large area samples. A $15 \times 15 \mathrm{~cm} 2$ sample requires $>200$ measurements and at least $15 \mathrm{~min}$ of measurement time to achieve $\mathrm{cm}$ scale spatial resolution. By using a 2D detector array and imaging along one dimension in parallel, the sample need only be translated in one dimension in order to map large area samples. As a result, the new expanded-beam system (that provides a line image of spectroscopic (350-1000 nm) ellipsometry) data can measure with similar spatial resolution in $<2 \mathrm{~min}$. (Currently a single 40 point line image can be collected in $10 \mathrm{~s}$ over a $15 \mathrm{~cm}$ width of PV material.) Incorporating the results of real time SE measurements, which provide good starting parameters in least-squares regression for the analysis of the imaging/mapping data, expanded-beam ellipsometry can be an effective in-line monitor of uniformity in PV production lines using roll-to-roll or rigid plate substrates. The goal of near future ( 2 years) efforts is to increase the speed by 10x and scale up the width by 4x. Then 1800 points could be mapped in a $1 \mathrm{~min}$ traverse of a $(60 * 120 \mathrm{~cm}) \mathrm{PV}$ panel.

\section{ACKNOWLEDGMENTS}

This work was supported by the National Development Agency KMR_12_1_2012_0225 project and grant TAMOP-4.2.2/B-10/1-2010-0025

\section{References}

[1] H. Fujiwara, "Spectroscopic Ellipsometry: Principles and Applications", Wiley (2007)

[2] “Handbook of Ellipsometry”, H. G. Tompkins, E. A. Irene (eds.), William Andrew Publishing (2005) 
[3] „Ellipsometry at the Nanoscale”, M. Losurdo, K. Hingerl (eds.) Springer (2013)

[4] Lohner T, Khanh NQ, Zolnai Z, ACTA PHYSICA SLOVACA 48(4) pp. 441-450. (1998)

[5] Serenyi M, Lohner T, Petrik P, Frigeri C, THIN SOLID FILMS 515:(7-8) pp. 3559-3562 (2007)

[6] Serenyi M, Lohner T, Petrik P, Zolnai Z, Horvath ZE, Khanh NQ, THIN SOLID FILMS 516:(22) pp. 80968100. (2008)

[7] P. Petrik, PHYS STATUS SOLIDI A 205(4) 732-738 (2008)

[8] Lohner T, Szekeres A, Nikolova T, Vlaikova E, Petrik P, Huhn G, Havancsak K, Lisovskyy I, Zlobin S, Indutnyy IZ, Shepeliavyi PE, JOURNAL OF OPTOELECTRONICS AND ADVANCED MATERIALS 11:(9) pp. 1288-1291. (2009)

[9] Szekeres A, Vlaikova E, Lohner T, Petrik P, Huhn G, Havancsak K, Lisovskyy I, Zlobin S, Indutnyy IZ, Shepehavyi PE, VACUUM 84:(1) pp. 115-118. (2009)

[10] Lohner T, Pongracz A, Khanh NQ, Krafcsik OH, Josepovits KV, Deak P, PHYSICA STATUS SOLIDI CCURRENT TOPICS IN SOLID STATE PHYSICS 5:(5) pp. 1337-1340. (2008)

[11] P. Kozma, B. Fodor, A. Deak, P. Petrik, Langmuir 26, 16122 (2010)

[12] P. Petrik, "Characterization of Nanocrystals Using Spectroscopic Ellipsometry", In: Sudheer Neralla (ed.), "Nanocrystals - Synthesis, Characterization and Applications", InTech, 2012, 29-40 (ISBN:978-953-51-0714-9)

[13] Dahal, L.R., Huang, Z., Attygalle, D., Salupo, C., Marsillac, S., Podraza, N.J., Collins, R.W.; IEEE Journal of Photovoltaics 3 (1), art. no. 6336774 , pp. 387-393 (2013)

[14] Aryal, P., Attygalle, D., Pradhan, P., Podraza, N.J., Marsillac, S., Collins, R.W.; IEEE Journal of Photovoltaics 3 (1), art. no. 6311418 , pp. 359-363 (2013)

[15] A.M. Hermann, C. Gonzalez, P.A. Ramakrishnan, D. Balzar, C.H. Marshall, J.N. Hilfiker, T. Tiwald, Thin Solid Films 38754 (2001)

[16] M.I. Alonso, M. Garriga, C.A. Durante Rincon, E.Hernandez, M. Leon, Appl. Phys. A 74, 659-664 (2002)

[17] Shota Minoura, Keita Kodera, Takuji Maekawa, Kenichi Miyazaki, Shigeru Niki, Hiroyuki Fujiwara , Journal of Applied Physics 113, 063505 (2013)

[18] J. Li, J. Scharf, M. Contreras, T. Furtak, R. Noufi, D. Levi, ibid

[19] Jian Li, Jie Chen, R. W. Collins, APPLIED PHYSICS LETTERS 97, 181909 (2010)

[20] Li, Jian; Chen, Jie; Collins, R. W. APPLIED PHYSICS LETTERS, 99, 061905 (2011)

[21] P. I. Rovira, R. W. Collins, Journal of Applied Physics 85, 2015 (1999)

[22] H. Fujiwara and M. Kondo Phys. Rev. B 71, 075019 (2005)

[23] M. Akagawa and H. Fujiwara, J. Appl. Phys. 110, 073518 (2011)

[24] H. Yoshikawa, S. Adachi, Japanese Journal of Applied Physics 36, 6237 (1997) 
[25] C. Major, A. Nemeth, G. Radnoczi, Zs. Czigany, M. Fried, Z. Labadi, I. Barsony, Applied Surface Science 255, 8907 (2009)

[26] S. Kageyama, M. Akagawa, H. Fujiwara. Phys. Rev. B 83, 195205 (2011)

[27] W. Guter et al., Appl. Phys. Lett. 94, 223504 (2009)

[28] A. Luque, JAP 110, 031301 (2011)

[29] Wojtczuk et al., in 35. IEEE Photovoltaic Specialists Conference, pp. 1259-1264 (2010)

[30] M. P. Suryawanshi, Materials Technology 28, 98 (2013)

[31] Todorov et al., Adv. Energy Mater. 2013, 3, 34-38

[32] Hongxia Wang: International Journal of Photoenergy, Volume 2011, Article ID 801292

[33] T. Omata et al, J. App. Phys. 105, 073106 (2009)

[34] S. L. Castro et al, J. Phys. Chem. B 108, 12429 (2004)

[35] K. Nose et al, Chem. Mater., 21, 2607 (2009)

[36] S. Wippermann, M. Vörös, D. Rocca, A. Gali, G. Zimanyi, and G. Galli, Physical Review Letters 110, 046804 (2013)

[37] M. Vörös, D. Rocca, G. Galli, G. T. Zimanyi, and A. Gali; Physical Review B 87, 155402 (2013)

[38] „IMAGING OPTICAL INSPECTION DEVICE WITH A PINHOLE CAMERA”; Pub. No.:

WO/2008/142468; International Application No.: PCT/HU2008/000058 Publication Date: 27.11.2008 International Filing Date: 23.05.2008, USA Application number: 12/601,410, Publication number: US 2010/0296096 A1, Priority Data: P 0700366, 23.05.2007, HU

[39] G. Juhasz, Z. Horvath, C. Major, P. Petrik, O. Polgar, M. Fried, Phys. Stat. Sol. (c) 5, 1081-1084 (2008)

[40] C. Major, G. Juhasz, Z. Horvath, O. Polgar, M. Fried, Phys. Stat. Sol. (c), 5, 1077-1080 (2008)

[41] C. Major, G. Juhasz, P. Petrik, Z. Horvath, O. Polgar, M. Fried, Vacuum 84, 119-122 (2009)

[42] M. Fried, G. Juhasz, C. Major, P. Petrik, O. Polgar, Z. Horvath, A. Nutsch, Thin Solid Films 519, 2730$2736(2011)$

[43] C. Major, G. Juhasz, M. Fried, Z. Horvath, Ambalanath Shan, Zhiquan Huang, R. W. Collins, to be published in Rev. of Scientific Instruments

[44] J. Li, J. Chen, M. N. Sestak, C. Thornberry, R. W. Collins, 34th IEEE Photovoltaics Specialists Conference, June 7-12, 2009, Philadelphia, PA, (IEEE, Piscataway NJ, 2008), pp. 1783.

[45] R. W. Collins, A. S. Ferlauto, G. M. Ferreira, C. Chen, J. Koh, R. J. Koval, Y. Lee, J. M. Pearce, C. R. Wronski, Solar Energy Materials and Solar Cells 78, 143 (2003) 